\title{
Bulgarian University Students' Learning Style Preferences in ESL Classrooms
}

\author{
Flora Komlosi-Ferdinand \\ University of Wales Trinity St David
}

\begin{abstract}
Correspondence concerning this article should be addressed to Flora Komlosi-Ferdinand, University of Wales Trinity St David, Carmarthen Campus, Carmarthen, SA31 3EP, United Kingdom.

E-mail: flora.komlosi@yahoo.co.uk
\end{abstract}

\begin{abstract}
Students' attitudes towards learning and the perception and beliefs behind them may have a profound influence on learning behaviour and learning outcomes. Teachers' awareness of such needs and preferences will result in more realistic and useful teaching strategies which, in turn, will have a facilitative effect on the learning process. Thus, learners should be given opportunities to express their own language learning preferences, especially in reference to the definition of objectives in general and awareness of strategies for learning. Moved with the conviction that learners and their preferences are of crucial importance in the development of learner autonomy, 74 students in Blagoevgrad, Bulgaria, were asked about their perceptions and preferences on ESL classroom activities. The results showed that learners were not always able to clearly define their preferences. This may be due to the fact that learning a foreign language is a culturally and psychologically different process than learning any other subject via the individual's first language. Thus, educators have the additional responsibility to help learners to find their learning strengths, and by cognitive training help students to expand their learning style preferences. Also, implications from this study clearly display that teacher training programmes should seriously examine and implement innovative ways of teaching English considering students' identity, character, and limitations.
\end{abstract}

Key words: Learning styles, ESL, foreign language education, language transfer, motivation

During the last century, the generally embraced teaching practices were focused on the preparation of a wide assortment of teaching materials that would equally benefit all students in the classroom. This approach assumes that knowledge can be obtained regardless of students' learning abilities and personality, failing to acknowledge the fact that learners have personal preferences and attitudes towards learning a foreign language. Attitudes in the foreign language classroom vary significantly and are conditioned by the students' character, previous experiences at school, and the local education systems' view on the teacher-student power structure. Although university education differs from learners' previous experiences at elementary and secondary school, approaches towards language learning are usually well established by that time. Some individuals may prefer memorising grammar rules or words and phrases and listening to the teacher's explanations and taking notes. Other learners may prefer to be actively involved in learning activities, inclined to participate in more action-based language learning strategies, considering this as a useful tool that enables them to communicate with others who know that language (Oxford, 1993 66-67).

These attitudes towards learning, as well as the perceptions and beliefs which determine them, may have a profound influence on learning behaviours and learning outcomes. Therefore, it seems that language teachers should take into account such learners' needs and attitudes in making decisions about the types of activities they conduct in the classroom. Also, identifying the learners' needs and preferences, and devising and implementing suitable activities will make teaching more successful. This will help students to develop more active and autonomous attitudes which allow them to take charge of their own learning. However, gaps between teachers' and learners' views may result in negative language learning outcomes (Mehrdad \& Ahghar, 2013, pp.102-103).

In this critical time of history, rapid demographic changes are swiftly shaping increasingly diverse societies. Globalization and an extensively technological world generate strong demand for English language learning around the world. Most developing countries assume that if their 
inhabitants are fluent in English, there will be expanded opportunities in the educational and economic sectors (Moores-Abdool, Yahya \& Unzueta, 2009, p.3). Therefore, teaching English and other foreign languages has recently become a world-wide phenomenon at all educational levels for people of all ages and backgrounds. This situation may present a challenge to teachers for developing successful teaching techniques that enhance both students' knowledge and motivation. Although considering students' learning style preferences may be a success factor in the classroom, these individual differences are rarely taken into account. The reason for this is that, except for very obvious cases, teachers may not even realise these differences in personalities. Therefore, deciphering motivation and learning style preferences is of fundamental interest to language programme designers, teachers, and administrators. Ideally, they should not only attract students to their institutions and educational programmes but need to provide them with the opportunity to learn according to their preferences and interests. Therefore, acknowledging different learning needs, demands, and attitudes is crucial for educators and for students themselves. Teachers should strive to use specific pedagogical techniques that strengthen and develop learners' autonomy. On the other hand, students should maintain their motivation in order to persevere and succeed in the challenging task of learning a foreign language (Schmidt, Boraie \& Kassabgy, 1998, p.2).

\section{Are learning styles important to consider?}

"It would seem on the face of it that required ways of using a language might be quite closely related to preferred ways of learning a language" (Widdowson, 1983, p.33 as quoted in Horowitz, 1986, p. 445).

Taking individuals' learning styles into account is a relatively new approach. Traditionally, it was not even considered as a concept per se, therefore, students' learning styles forcedly had to coincide with the educator's teaching style. The power structure in education was strongly teacher centred, while students were expected to grasp the knowledge delivered. It can be said that the history of education had its dawn in households, where parents passed the necessary skills to their children. In that case, theoretical and practical skills were both sharpened in ideal ways:

1. Parents knew the character, strengths, and limitations of their child(ren) and could find the most suitable approaches to educate them.

2. Social and practical skills were both developed and tailored exactly for the needs of the child, considering the most likely demands he/she could meet later in life.
3. Education was not only focused on general subjects, but aimed for a holistic development with the intention of preparing children for life.

This individual approach grew impossible to maintain when education became accessible, and later obligatory, to the masses. Students with very different personalities, interests, and backgrounds were asked to attend classrooms where the educator's attention was divided in many directions. Moreover, due to some countries' governmental policies, the focus in education shifted towards the goal of children passing the exams with good marks, with an unsatisfactory emphasis on real cognitive development. However, some positive changes in those tendencies can be observed. A growing body of research suggests that in a growing number of institutions, students' learning preferences are taken seriously, and the findings are supported and implemented by educators and administrators alike (Mulalic, Shah \& Ahmad, 2009, p.9).

Driven by the desire to place more attention on students' individual (language) acquisition differences and processes, the following seven points were collected as factors that help to improve the speed and quality of learning (Moenikia \& Zahed-Babelan, 2010, p.1171)

- Visual (spatial): The using of pictures and images

- Aural (auditory-musical): The using of sound and music

- Verbal (linguistic): The using of words, both in speech and writing

- Physical (kinaesthetic): The use of one's body, hands, and sense of touch

- Logical (mathematical): The use of logic, reasoning, and systems

- Social (interpersonal): Group works, brainstorming, or learning with other people

- Solitary (intrapersonal): Working alone and self-study

The list of these seven points is a valuable tool in order to gain a fuller picture about students' preferences and/or abilities to access and absorb information and knowledge. However, deciphering the learning style of an individual lies in the combination of these points. As Mehrdad and Aghar (2013, p.103) point out, the term 'learning styles' is used to include three behavioural aspects of an individual: 1) cognitive style, describing patterns of inclinations and attitudes that influence what the student will pay the most attention to in a learning situation; 2) the likelihood to seek situations consistent with one's own learning patterns; and 3) the inclination to apply specific learning strategies and to avoid others. 


\section{Factors determining learning styles}

Learning preference and capacity is empowered by many different factors such as (personal) circumstances, changing motivation, teachers' attitudes, and classroom conditions. Since these factors are not completely stable throughout time and evolving personalities, it is safe to say that there is no right or wrong permanent mix of traits that will work for an individual in all domains. Therefore, considering that each student has specific preferences for learning, it is easy to see the trouble of having many small sub-groups in one classroom with a teacher prepared to satisfy the peculiarities of each learning category. The analysis and grouping of the most similar learning style preferences may offer a temporary solution to this challenge. However, after reflecting on their learning, a few students reported that they were able implement some of their already well-working strategies and, based on them, develop new skills to succeed in their less dominant learning styles over time. This accomplishment may be of great importance, considering that the more an individual is conscious of his/her learning styles, and the more he/she is capable of expanding them, this will lead to more academic achievement and success later in life. Therefore, the value of the consciousness of one's own learning styles goes beyond academic success. This process shapes the students' identity and the way experiences are internally represented and acknowledged, and improves the capability to recall previous material or apply structures in new circumstances (Mulalic, Shah \& Ahmad, 2009 p.10).

\section{Rights versus abilities - can students determine their own learning needs?}

Nowadays, many teachers experience student resistance when establishing educational activities in the classroom. Some students prefer more opportunities to participate in free conversation and dialogues, expressing their desire towards a more communicative approach. On the other hand, there are students who would favour more emphasis on grammar teaching. Collaboration can hardly be forced, but it can be negotiated. Although educators often acknowledge the need to decipher the ways in which learners differ in terms of needs and preferences, they may fail to discuss students' opinions when conducting language activities. This reluctance to take such preferences into account may be found in the belief that learners are generally not capable of understanding, analysing, and communicating what they want or need to learn, and they lack a clear strategy to achieve learning success unless especially directed by an educator. Moreover, in most societies, the teacher-student power structure in the classroom is established in a rather rigid way, leaving no opportunity for learners to participate in decision-making on educational methodology. In most cultures, this would be even seen as highly inappropriate, given educators' established role in society (Bada \& Okan, 2000, pp.1-2). Therefore, do students have the right and/or the capacity to express their learning style differences and expect them to be considered? Csíkszentmihályi's theory argues that an individual's attentiveness, motivation, and ability to concentrate will flourish when tasks and skills are on equal levels and both are on the high end of the spectrum. However, when the task is too hard and the student's skills are low, the psychological and emotional outcome may result in anxiety. On the other hand, when the challenge is considerably lower than the learner's skills, the completion of the task may produce boredom (Schmidt, Boraie \& Kassabgy, 1998, p.6). Thus, carefully balancing students' learning style preferences, skills, and the learning task may lead to more motivated and engaged individuals, resulting in more fruitful education intellectually, emotionally, and economically.

\section{First-language influence on second-language acquisition}

"Language from a multilingual perspective
can be defined as a system of signs resting
upon an underlying conceptual system that
is unique to each culture. This definition
implies that there is a linguistic and a
conceptual level, which operate together
in language processing and that the
conceptual level is culture-specific. The
conceptual system pulls together cognitive
constructs and knowledge; language reflects
this system"

(Kecskes, 2008, p. 31)

Second or foreign language students use their first language structures and diverse strategies to accelerate the acquisition of the target language. This action occurs either consciously and intentionally by learners in order to overcome the limitations of their knowledge, or unconsciously because of the complete lack of proficiency in a specific context, or because the material learned was not fully automatized. This process is called "language transfer" (Karim, 2003, p.49). This is corroborated by Chomsky' universal grammar theory, in which he argues that individuals process and construct language through a profound structure that allows them to transfer their first language (L1) grammar skills to the target (L2) language (Chomsky, 1979, p.181-184). Since all individuals learn some language skills (including sign-language) 
when acquiring their first language, this expertise is naturally transferable to the desired foreign language learning strategies. Therefore, both educators and learners should be aware of the degree L1 structure and skills are transferred in ESL classrooms, enhancing or hindering the acquisition of L2. Consciousness of such practices may be an invaluable tool to determine further educational strategies and instructional methods (Karim, 2003, p.53).

Karim (2003, p.54) proposes six critical points for how to convert students' $L 1$ transfer into an advantage:

1. The careful observation of learners' $L 1$ transfer strategies may help to comprehend the positive influences of such processes, directing them into correct $\mathrm{L} 2$ acquisition techniques.

2. Educators considering the advantage of L1 education already received may benefit from students' previous linguistic knowledge, skills, and mental schemata.

3. Once learners' positive transfer skills are identified, teachers may help students to use these skills effectively in L2 acquisition.

4. Educators' in-depth knowledge of their students transfer skills may help them to categorise students into corresponding studygroups according to their needs and abilities.

5. When the L1 and L2 possess similar grammar or structures, students may need additional instruction on how not to rely on L1 transfer in all domains of second-language learning.

6. The study of learners' early transfer abilities or negative transfer practices may help educators to identify possible common mistakes and to develop accurate and effective learning strategies.

Wang (2014, p. 59) reinforces the importance of directing L1 transfer skills wisely. He argues that, from a psychological perspective, learning in general is an accumulative process. Therefore, past educational experiences and activities greatly mould learners' attitudes and the courage to face new tasks where previous knowledge may not be completely useful. Thus, the amount of skills and knowledge acquired by an individual may shape his/her perceptions about new learning processes in the future. It may be of key importance to train learners how to direct their transfer skills from old to new situations. In foreign language learning, this strategy may help students to control their own learning, develop independent learning skills, find their authentic learning style preferences, and expand their intrinsic motivation and grit.

The general concept of first-language influence on second-language acquisition can further be analysed by its application according to the four main skills, namely listening, reading, writing, and speaking. It is also noteworthy to examine students' preferences for working individually, in pairs, in small groups, and in large groups.

\section{Individual versus group working preferences}

Some research suggests that individual learning in ESL contexts may be successful in groups of mixed ability, where low-achieving learners may need some additional time to gain sufficient knowledge in order to catch up with their peers. This hypothesis is based on the observance that learners may devote more attention and focus to a greater degree when they are not distracted by the other members of the group but are focusing on their own task (Arias \& García, 2013, p.4). However, many other studies maintain that cooperative learning develops not only language learning skills, but builds character, shapes students' emotional intelligence, and develops better strategic skills (Reinders 2010, p. 40). Moreover, as shown in a study with more than one hundred college students, group learning enhanced class attendance and academic performance due to the pressure from the rest of the peers (Grimm, 2004, p. 1, 2). Competition in group-learning settings may be regarded as another factor that intensifies the desire to achieve more, to use the language skills acquired during the lesson, and to develop intrinsic motivation and grit. Also, competing against other groups awakens students' natural instinct to be the best when compared with the rest. This idea seems to be greatly supported by the Situated Cognition Theory developed by Brown, Collins, and Duguid (1998, p. 32), that combines learners' problem solving skills and domain specific knowledge for the success of collaborative learning (Grimm, 2004, p.3). Vygotsky's social cognition theory argues for the benefits of group-learning too (Frawley, 1997, p. 520). In his viewpoint, social interaction and shared problem solving are fundamental for full cognitive development. Vygotsky argues that while working in a group, peers' reactions may provide feedback to the individual on the actions displayed and reinforce acquisition of knowledge. Moreover, every step in the path of learning emerges and solidifies first in the social level and only after the expected reaction from peers or teachers can it become intrapsychological (Grimm, 2004, p. 4). Finally, Long and Porter (1985, p. 208-211) collected at least five points that benefit students during group work.

1. Increased opportunities to practice the language

2. Group work promotes the opportunities for students to polish the quality of their language skills.

3. Emerging errors during group work help educators to correct specific individual needs.

4. Reduces performance anxiety (in contrast with 
when the student is asked to perform a task alone in front of the whole auditorium)

5. Through the variety of characters (and emerging errors) group work motivates students to express themselves more freely.

\section{Listening and visual skills}

\begin{abstract}
"Listening, the recognition and interpretation of auditory stimuli is accepted as one of the most important features in children's learning... Listening skills are generally considered one of the four major components of language arts. However, it is widely recognized that the ability to listen attentively and critically is generic to children achieving success in all academic areas as well as in life in general"
\end{abstract}

(Buttery 1980, p.181)

In second language learning, listening is one of the most complex skills to acquire. Listening occurs in a variety of domains and contexts coming from individuals with different accents, volume of voice, verbal versatility, intelligence, and communication skills. Thus, for foreign language learners, listening and understanding the words and the grammar structures used in a particular situation and internalising the message sent can be a tedious and overwhelming challenge. This is particularly true when the learner is not only a passive observant of the events (i.e. watching TV, listening to a lecture, or observing a group of people interacting) but he/she is required to be engaged in a dialogue. Therefore, to be able to minimally function in the target language, it is necessary to develop good listening skills in order to have a general understanding of the situation and to decipher the other speaker's intention.

Although essential, teaching listening skills effectively in a second-language learning context has been neglected for a long time. Unfortunately, the challenging nature of teaching this skill has led professionals to overlook this problem. The complications of ignoring such difficulties may lead to students never fully developing listening skills, which, in turn seriously hinders further development in the acquisition of the target language. However, teaching listening has started to evolve recently. With new technologies in the classroom, the classical audio tools have given way to new activities that engage multiple senses while sharpening learners' auditory senses. TV, videos from the Internet, and video clips often with subtitles help students to establish a clearer picture in their minds about the information they heard. Moreover, some research suggests that audiovisual aids greatly enhance the comprehension of listening materials and have beneficial effects on language processing (Folley, 2015, p. 11-14).

When talking about listening and visual skills, body language, gestures, and facial cues should by no means be neglected. This is particularly true since human interactions and the understanding of the other individual(s) are often based on grasping the non-verbal cues emitted. Empirical studies show that English L2 learners exposed to active communication sessions with an English native speaker over an extensive period of time demonstrated that gestures played a crucial role in learning success (Gullberg \& McCafferty, 2008, p. 137). Therefore, gestures and body language in general help with internalising the message, especially when they are used in a culturally comprehensible context.

\section{Reading and comprehension skills}

"Reading is a conscious and unconscious
thinking process. The reader applies many
strategies to reconstruct the meaning that
the author is assumed to have intended. The
reader does this by comparing information
in the text to his or her background
knowledge and prior experience."

(Mikulecky, 2008, p. 2)

Samuels (2007, p. 1) states that to fully understand a text, the individual must be able identify the words on the page and construct their definition. Therefore, reading and the comprehension of written material is crucial for the success in the acquisition of a foreign language. Reading instruction constitutes a big part of language learning: the usage of textbooks, worksheets, vocabularies, and online exercises all require the students to understand the meaning of the written text. Researchers Kintsch and van Dijk (1978), Rumelhart and Ortony (1977), Winograd (1977), and Rumelhart (1980) developed an information processing system to better comprehend how individuals process what they read. According to them, there are some facets of humans' information processing systems that interact continuously. When the individual concentrates on the already-known words and constructions during reading, this action is identified as a "concept-driven" or "top-down" mode. The opposite happens in the "data-driven" or "bottom-up" approaches, when the reader predominantly focuses on the information yet to be deciphered and on the peculiarities of the material to be understood. Therefore, the reader actively processes components of the text, while contrasting and comparing that information with his/ her previously acquired knowledge. At this phase of the task, prior understanding and knowledge initiates a presupposition about the text's full meaning. This 
reciprocal process extends until the individual has a clear grasp of the text and his/her previous knowledge, eventually leading to comprehension of the material. As seen, reading and comprehension are complex tasks to perform. Reading in a second language, however, has additional complications and barriers to overcome. Most second-language learners use their first-language mental schemata to determine the points to notice and the strategies to apply when constructing the meaning, and ultimately when interpreting the message of the material. However, reliance on the readers' first-language processing system may significantly distort the meaning of the text. Therefore, when teaching how to read in a second language, additional care has to be placed on clarifying surging biases based on the individual's cultural background and first language (Mikulecky, 2008, p. 1-2).

When considering the acquisition of any foreign language, it is important to mention the role, limitations, and accurate definition of fluency. Being a fluent reader in the individual's first language should not be automatically assumed that he/she will have the same ability in the foreign language context. According to Lems, Miller, and Soro (2010, p. 148), fluency is defined when a person has nativelike proficiency in the target language and has the ability to synchronously decipher, understand, and internalise the message of the text.

Achieving fluency in a second language may be a complicated task. In most cases language, culture, reasoning patterns, and social-behavioural norms are strongly connected, shaping the readers' conceptions of the world. Therefore, readers with diverse cultural and/or linguistic backgrounds may form different opinions on what a text signifies (Karim, 2003, p. 49). Thus, educators should not conclude that individuals who have excellent reading skills in their native language can produce the same speed, quality, and comprehension skills while reading in a foreign language. Consequently, professionals teaching a second language to students should be aware of the importance of not only focusing on vocabulary, syntax, and fluency but advising students to learn the target language within an appropriate cultural context. This "secondary literacy" teaches individuals not to rely on their first language, culture-specific interpretations, or biased cognitive structures when interpreting the text read.

\section{Writing and analytical skills}

The number of studies on writing in a second language has traditionally been unsatisfactory in comparison with the data available on the analysis of the other main skills (Krashen, 1984, p. 41).
Some researchers suggest that students' composing processes in a second language are largely similar to the schemata they use in their first language (Raimes, 1985, p. 231). This may concern both students and educators, since writing (along with the other three main skills) largely influences learners' capacity and accuracy in correctly acquiring a second language. Based on empirical research, Williams (2012, p.1) suggests three major areas where writing benefits, consolidates, and polishes a student's L2 development.

1. A comfortable pace - Students usually have more time to analyse, build, and construct the sentences in comparison to listening or speaking exercises.

2. Long lasting record - writing leaves stable and reinforced records in students' memories. This, in turn, enhances further positive cognitive processes in the internalisation of the target language.

3. The demand for greater precision - Writing activities require continuous and careful reviewing of students' explicit knowledge; this leads to more cautious planning, monitoring, and structuring of the material to be produced.

Writing and reading skills in a second language have overlapping dimensions; while readers are required to decipher the formal and cultural/social facets of the text, writers are expected to encode them. Therefore, writing should always be seen as socially and culturally placed. Therefore, during writing exercises, teachers are urged to be aware of the pitfalls of breaking down such tasks into solely component skills, ignoring the cultural significance of the text. Thus, as writing greatly consolidates learners' perceptions and comprehension of the cultural dimensions of the target language, a holistic approach to such exercises is highly recommended (Archibald, 2004). This, in turn, will help learners to consciously develop specific writing skills that will satisfy any reader-sensitivities of the target audience (Myles, 2002, p. 2).

While cultural components are fundamental aspects of writing in an L2, Tsang and Wong (2000, p. 41) propose that explicit grammar instruction enhances writing skills to a great extent. In their research, they state that students with intensive grammar training had increased readiness and ability to use mature syntax in their writing. Furthermore, Yau (1991, p. 268) argues:

"Although we should not cripple our students' interest in writing through undue stress or grammatical correctness, the influence of second-language factors on writing performance is something we have to reckon with and not pretend 
that concentrating on the process would automatically resolve the difficulty caused by these factors."

\section{Speaking and creative skills}

Speaking is a fundamental part of foreign-language education. Communication, syllabus contents, and any measurable learning outcome would be much more complicated to achieve without the spoken part of the target language in the classroom. According to Burns (2012, p.165) many students display the following attitudes in foreign language classrooms when asked to speak:

1. Most students have the ability to read and write well, but they lack the ability to transfer the same skills to produce speech.

2. Many learners express debilitating fear when asked to talk in the classroom due to shyness and lack of confidence.

3. Some students' speech has more resemblance to the act of reading a book. Natural expressions and intuitive communication seldom take place in foreign language classrooms.

4. Although some students would like to practice more speaking, the hardship of combining accurate vocabulary and grammar prevents them from succeeding.

Speaking in the desired second or foreign language is often regarded as synonymous with apprehension and anxiety among learners. Unfortunately, nervousness to perform well in this skill may even hinder the progress of L2 acquisition and/or have detrimental effects on learners' motivation to practice their communication skills in the target language at all. Nowadays, the use of communication-oriented strategies in foreign language classrooms places a considerable amount of pressure on students. Therefore, it is the educators' responsibility to consider students' individual capacities, limits, and character and to alleviate this anxiety while assisting them to achieve desired performance objectives in the target language (Tanveer, 2007, p. 1).

Researchers and foreign language acquisition specialists also reinforce the idea that there is a specific kind of anxiety while leaning and speaking a second language, differentiating this from the nervousness displayed while learning other skills or subjects (Guiora, 1983, p.8). According to them, this may be due to the fact that foreign language acquisition is a "profoundly unsettling psychological proposition" because it may pose a threat to the learner's cultural identity and world view. Therefore, is there a connection between speech anxiety in the learner's first-language and the target language to acquire? Individuals may be nervous in situations involving public speech regardless of whether they use their native language or not. However, as Tanveer (2007, p.3) points out:
"Anxiety experienced when speaking in a second/foreign language seems to be more debilitating than the anxiety experienced when speaking in the first language. Anxiety while communicating in other than L1 goes a step further with the addition of the difficulties associated with learning and speaking a foreign language. In a foreign language, a speaker has to look for suitable lexis, has to construct an appropriate syntactic structure and needs to use a comprehendible accent, plus the demanding tasks of thinking and organizing ideas and expressing them at the same time".

Educators are presented with a great challenge when teaching how to speak a second language. The acquisition of communication and speaking skills from a holistic perspective may enhance students' performance and their motivation to eventually master such skills. However, teachers should be knowledgeable about the proper nature of speaking competence and how diverse aspects of this skill relate to each other (Burns, 2012, p. 166). Johnson (1996, p. $155)$ points out that "speaking is a combinational skill that involves doing various things at the same time."

In their "Second Language Speaking Competence" framework, Burns and Goh (Burns, 2012, p. 167) present a model that involves language knowledge, core speaking skills, and communication and discourse strategies. According to them, learning to speak in a foreign language implies mastering the abovementioned skills in order to display fluency, accuracy, and culturally appropriate attitudes.

Therefore, a combination of the following three aspects should be considered to enhance speaking skills in foreign language classrooms:

1. Knowledge of the language itself: Correct knowledge of the sound patterns (being able to pronounce the language), grammar, vocabulary (lexis and spoken structures), and the speech's correct pragmatical and social embeddedness

2. Core speaking skills: Learners' capabilities to process speech accurately and to improve fluency. It also requires aptness to structure the speech based on previous clues: observing anterior failures in understanding, foregoing utterances and communication-mismatches, as well as directing and controlling the flow of speech as it develops. 
3. Communication Strategies: Learning and enhancing cognitive approaches and strategies in order to counterbalance deficiencies of knowledge in the target language. Also, developing metacognitive skills, such as the conscious planning and structuring of the speech, and mastering interaction competence by asking for clarification, repetition, and confirming correct understanding (Goh \& Burns, 2012, p. 53).

\section{Hypothesis}

The magnitude of the task of deciphering global linguistic behaviour, motivation, and learning style preferences as a whole lays beyond the possibilities of this research. However, in recent times, there has not been such a study carried out on Bulgarian written in the English language. Therefore, the above-mentioned four main skills and the individual versus group working preferences were considered an optimal base where Bulgarian students' attitudes towards L2 acquisition can be analysed.

According to my hypothesis, Bulgarian university students were rather reluctant to participate in most educational activities carried out in the ESL classroom. Prior to this study, during informal discussion with colleagues and learners, most students expressed clear ideas about their dislikes, yet most of them could not identify their own learning strengths or learning style preferences. Only a few students suggested having a clear learning strategy or a learning style preference. However, as a paradox, many declared to be very motivated to learn English well and declared to be working hard in order to achieve this goal. Therefore, I was intrigued to unveil 1) what learning strategies and activities are perceived as the most beneficial by the learners and 2) to what extent students are conscious of their learning style preferences.

\section{Method}

A survey was conducted in order to investigate whether learning style preferences can be considered a decisive factor for success in EFL classrooms among university students in Bulgaria. In order to collect data, quantitative research methodology was used by inviting students to complete paper-based questionnaires.

\section{Participants}

The study was conducted in two universities, one private and one national, in Blagoevgrad, Bulgaria.
The number of participants was 74: 23 male and 51 female students between the ages of 16 and 57 years old (See Figure 1). For the purpose of this study, a convenience sampling method was used to determine the appropriate subjects. Individuals attending university courses were the most convenient to select because, at least hypothetically, none of them were forced to attend lessons. Therefore, supposedly, they were all motivated to some degree to succeed in their respective studies. At the time of the research the majority of the learners were pursuing bachelor and master's degrees related to linguistics or/and English language in an array of degree programmes at the university and were studying at varied language levels (intermediate and advanced). Some of the students, however, attended specific EAP (English for Academic Purposes) courses, while some who participated were enrolled in programmes of English for general purposes.

The wide age gap of the students was not considered an inconvenience in this case since some scholars suggest that attitudes start to appear at the age of 10 and are clarified and consolidated during adolescence (Huget \& Llurda, 2001, p.271). Therefore, at the time the study was conducted, all participants theoretically had clear learning style preferences and established learning habits. Moreover, Grimm (2004, p.1) suggests 'generalizations about the whole population can be expanded when more people at different grade levels are studied'. Before the questionnaires were distributed in the classroom, the research objectives were made clear and the opportunity to participate or withdraw at any moment was given to all participants.

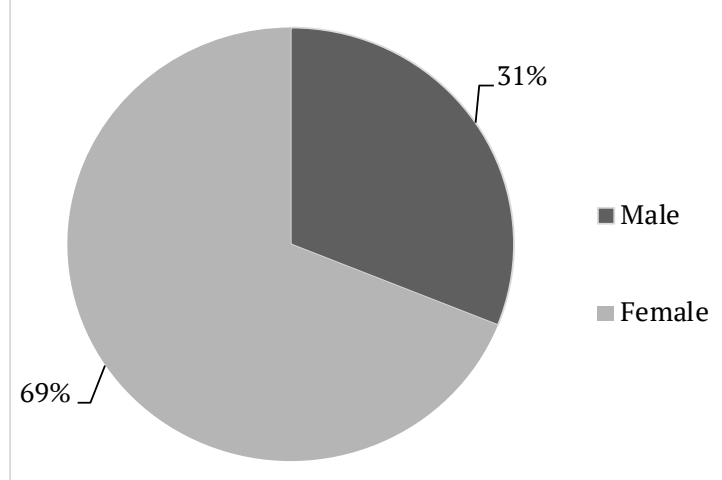

Participants by gender

Figure 1. Participants by gender.

The proportion of the genders in this study reflects the general percentage of males and females attending university courses and specific English language courses in Blagoevgrad, Bulgaria. 


\section{Materials}

The data was obtained by a self-completed questionnaire developed by the researcher especially for this study. The chosen quantitative research method aimed to collect self-reported data from students with the intention of describing existing conditions or identifying points of reference to be used for comparing conditions or determining the relationships between specific events (Dörnyei \& Csizér, 2012, p. 74).

The questionnaire itself consisted of some closedended questions and some other questions where the answers had to be marked on a five-point Likert-scale (from 1-strongly disagree to 5-strongly agree).

Although the study was made in Bulgaria and mostly with Bulgarian students, the questionnaires were written and completed in English. However, before administering the instrument, the students' understanding on the wording and on the meaning of the questions was verified. Moreover, at any time participants could ask, clarify, and have the meaning of some particular words or questions in the questionnaire translated.

\section{Procedure}

To guarantee the scientific validity and understandability of the questionnaires, a pilot study was conducted. Two Bulgarian and two foreign researchers on education and linguistics were asked to read the questionnaire and provide advice on the clarity, wording, and content of all of the items. Moreover, a group of six students gave their opinions on the questionnaire. After including some of the suggestions, paper-based questionnaires were administered to the students by the teachers working in the respective institutions. All of the students were informed by their English teachers about the objectives of the research. Therefore, all participants were aware that no monetary compensation or better grades were offered as a reward for participating. Students were also informed about the anonymous nature of the questionnaire and how their names would not appear in any article, study, or statistics. Also, a short paragraph at the beginning of the questionnaire informed students about their right to withdraw at any moment.

The questionnaires were filled out in the classroom; however, no questions were discussed aloud among the students and a respectful attitude could be observed. The distribution of the questionnaires took place in May 2016. This was considered one of the most opportune moments since learners were not overstressed or too busy with exams.
The results were based on the five-point Likert scale questionnaire, from "strongly disagree" to "strongly agree". Two main categories were separated according to gender and percentages were taken for each group/ question.

\section{Results}

The data obtained via the 'students' learning styles preferences' questionnaire was analysed with the intention of shedding light on students' inclinations, biases, and desire to participate in different educational classroom activities. Through the study, gender differences, language anxiety, decisiveness, and learners' choices for working individually, in pairs, small groups, or large groups in the ESL classroom were examined.

\section{Individual versus team working preferences}

The findings showed some clearly marked opinions on individual versus group working preferences among Bulgarian students. To the question "Do you like learning individually?" (See Figure 2) females expressed mostly positive attitudes by 59 percent, while males' viewpoints were rather divided on the matter. When asked "Do you like learning in pairs?" (See Figure 3) both genders' opinions were divided. The most positive viewpoints could be observed when asked "Do you like learning in small groups?" (See Figure 4). Almost half of the participants favoured working in small groups, while the third of the males expressed dislike and 30 percent of the females gave neutral answers. When asked "Do you like learning in large groups?" (See Figure 5) viewpoints were inversely proportional to the answers given to the question dealing with working in small groups. Half of both male and female students disliked or strongly disliked collaborating in this format, while one-third of the males expressed positive opinions while almost onethird of the females remained neutral.

\section{Listening/visual skills}

To the general question " $D$ o you like learning by listening?" (See Figure 6) 61 percent of male students answered positively, while only the half of the female students were of the same opinion. Females did slightly move towards being neutral on this topic. Opinions were more clearly expressed when asked more in detail about listening exercises. When presented with the question "Do you like learning from radio and/or podcasts?" (See Figure 7) both male and female students expressed their dislike by 40 percent. Although on both sides there were 35 percent positive 


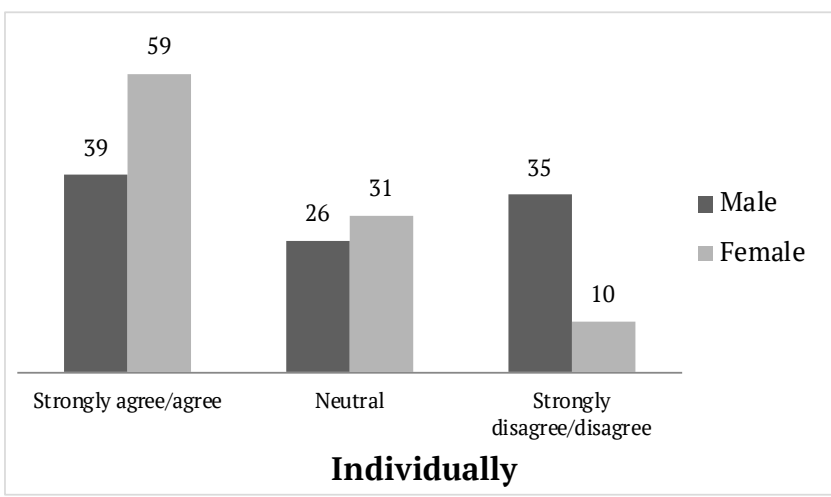

Figure 2. Learning individually (percentages).

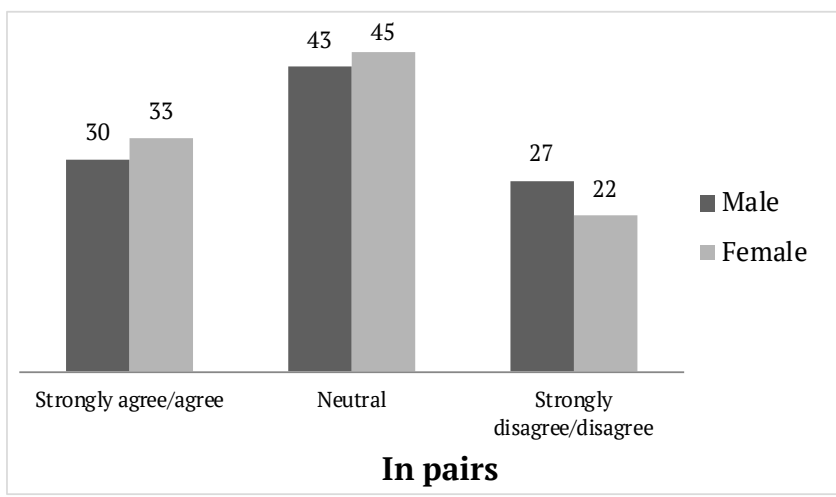

Figure 3. Learning in pairs (percentages).

answers, yet the high number of negative answers on only listening without visual aids shows that this option may not be very successful.

When considering the question "Do you like learning from CDs, applications or online?" (See Figure 8) male students' viewpoints were divided by almost the same number of answers on the positive and on the negative sides leaving 26 percent with neutral standpoints.

When considering the question "Do you like learning from CDs, applications or online?" (See Figure 8) male students' viewpoints were divided by almost the same number of answers on the positive and on the negative sides leaving 26 percent with neutral standpoints. On the same topic, female learners were more favourable, almost half of them.

About 40 percent showed neutral attitudes on this kind of activity. A positive turning point was clearly observable when answering the question "Do you like learning from television, videos and films?" (See Figure 9). About 75 percent of both sides agreed that listening exercises were enjoyable. Viewpoints on the topic " $D o$ you like songs, karaoke - fill in the missing words?" (See Figure 10) were mostly neutral, clearly moving towards negative in the case of males. When asking students "Do you like getting information from guest speakers?" (See Figure 11) the answers were divided between neutral and positive, leaving very few opinions on

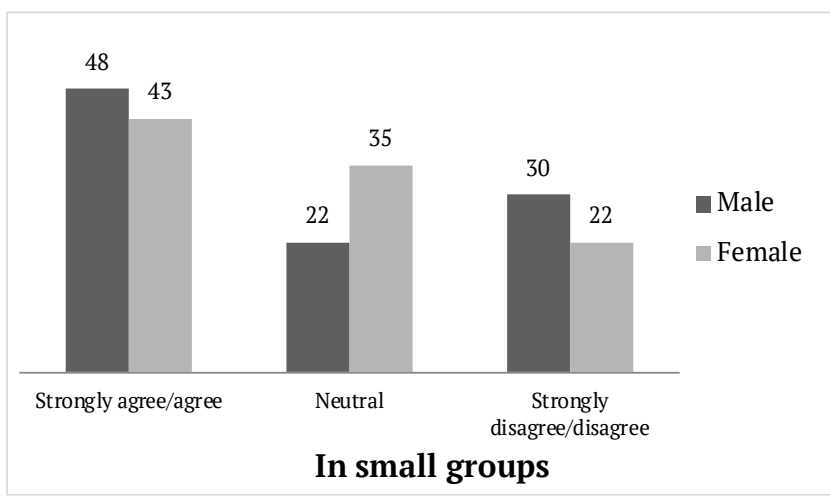

Figure 4. Learning in small groups (percentages).

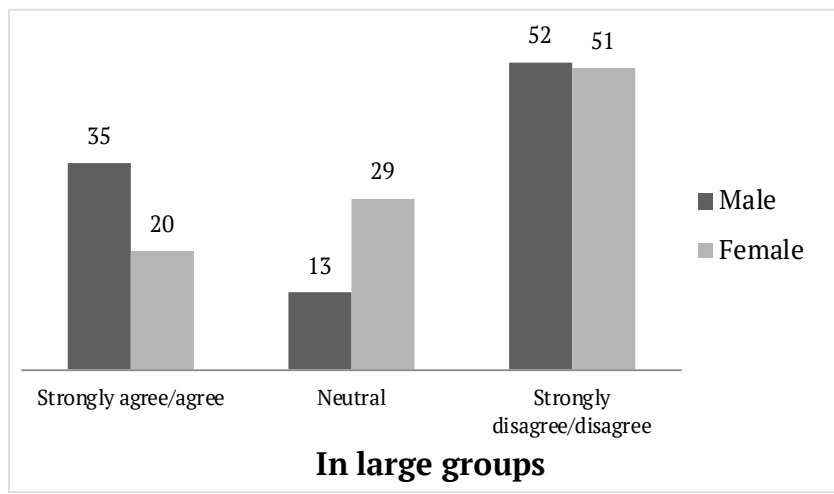

Figure 5. Learning in large groups (percentages).

the negative sides. The final question on listening and visual skills "Do you like getting information from planned visits to museums, galleries, etc..?" (See Figure 12) had a rather neutral feedback on both sides, the rest of the opinions being equally favourable and disliked by female students, while male students had a slightly higher number of positive than negative thoughts on this matter.

\section{Reading/comprehension skills}

Bulgarian students' answers show enthusiasm when asked "Do you like learning by reading?" (See Figure 13). The majority of both male and female students found reading an enjoyable activity. On the other hand, when asked "Do you like learning by reading and taking notes?" (See Figure 14) fewer positive, more neutral, and even some negative answers were given.

The answers to the question "Do you like learning from analysing written material?" (See Figure 15) showed similar attitudes. Half of the male students expressed neutral opinions, while 39 percent liked this activity. Female students showed a more positive approach with 61 percent in favour of analysing written material, while the rest's viewpoints were divided among neutral or negative answers. The question with the most negative answers was "When 


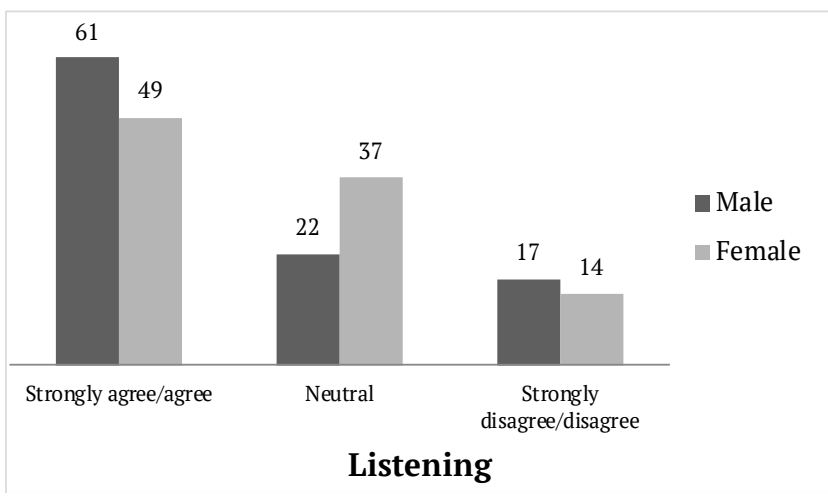

Figure 6.Doyou like learning by listening?(percentages)

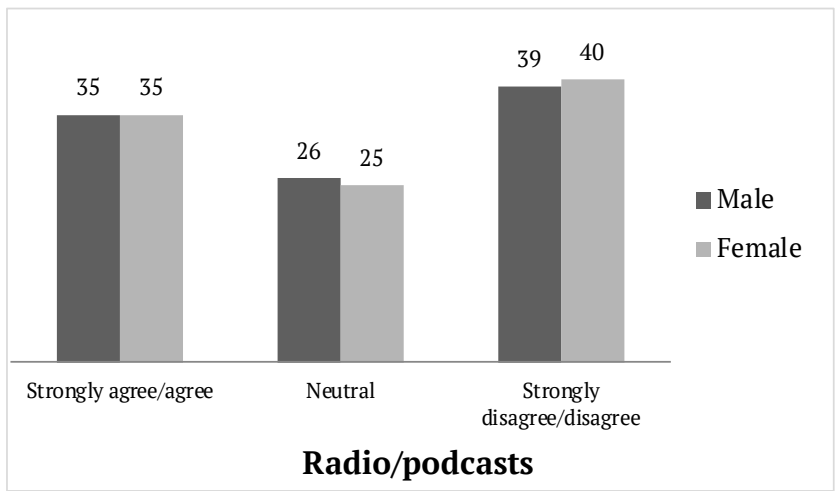

Figure 7. Do you like learning from radio and/or podcasts? (percentages)

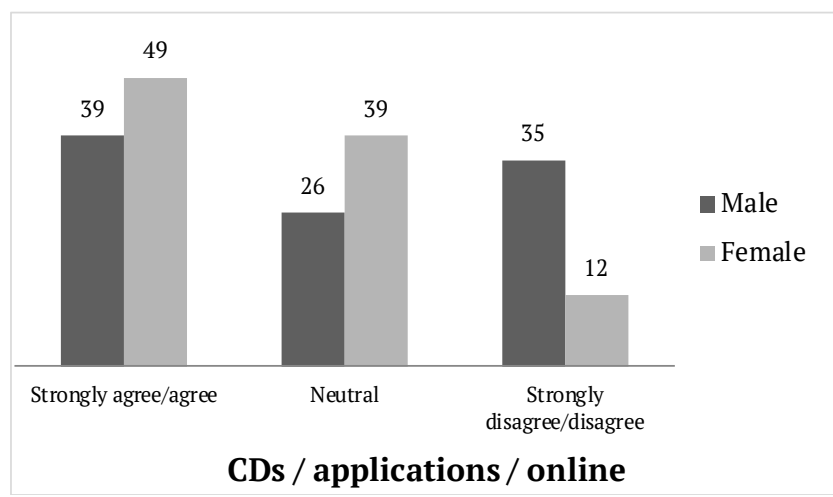

Figure 8. Do you like learning from CDs, applications or online? (percentages).

learning new vocabulary do you like learning by reading without looking up or translating words?" (See Figure 16). Both male and female students agreed by about 40 percent that assuming or guessing the meaning of new words (even if placed in an already familiar text) was not preferred by them. To the same question about 25 percent of both genders reacted neutrally and only an average of 32 percent enjoyed this challenge. When asked "Do you like learning from the whiteboard?" (See

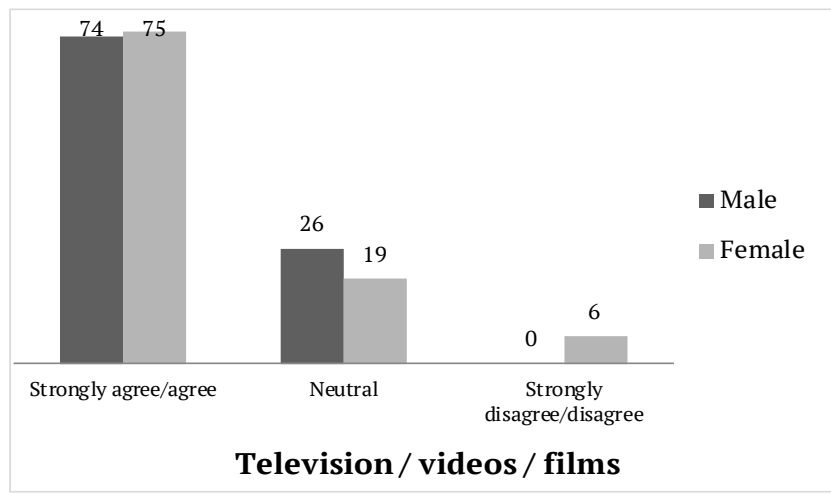

Figure 9. Do you like learning from television, videos and films? (percentages).

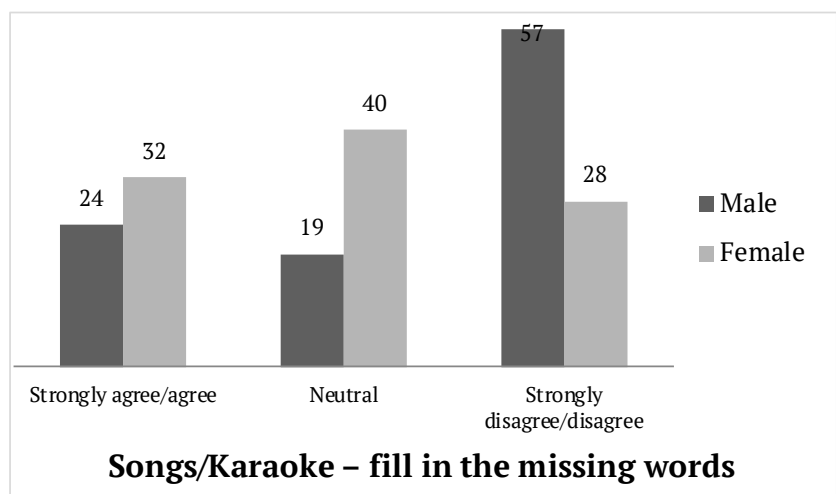

Figure 10. Do you like songs, karaoke - fill in the missing words? (percentages).

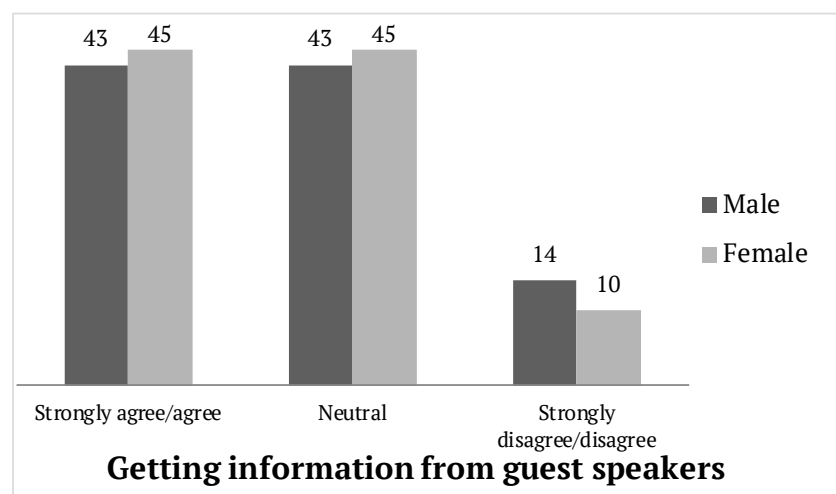

Figure 11. Do you like getting information from guest speakers? (percentages).

Figure 17), students showed evenly neutral attitudes, except female students where 61 percent were favourable of such an activity. Lastly, when asked " $D$ o you like learning from pictures, posters and/or cards?" (See Figure 18) half of the students agreed or strongly agreed on the likeability of this activity. However, 39 percent of the males and 29 percent of the females showed neutral attitudes, which left the category of disagree/strongly disagree with rather weak support. 


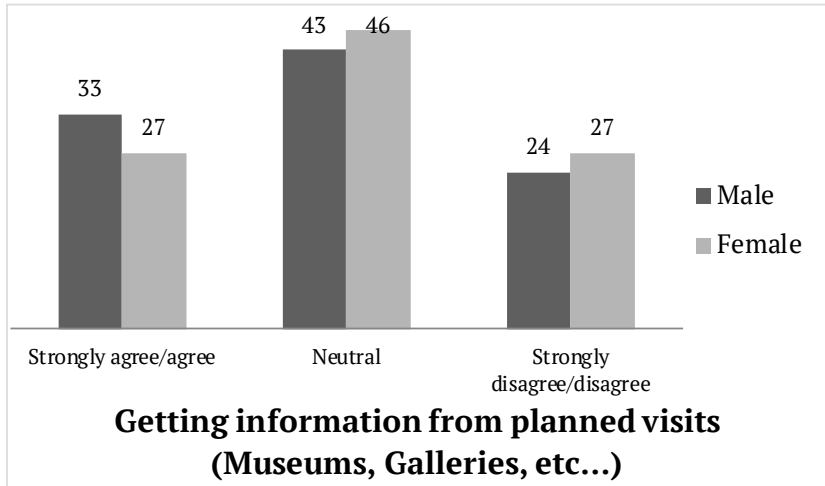

Figure 12. Do you like getting information from planned visits to museums, galleries, etc..? (percentages).

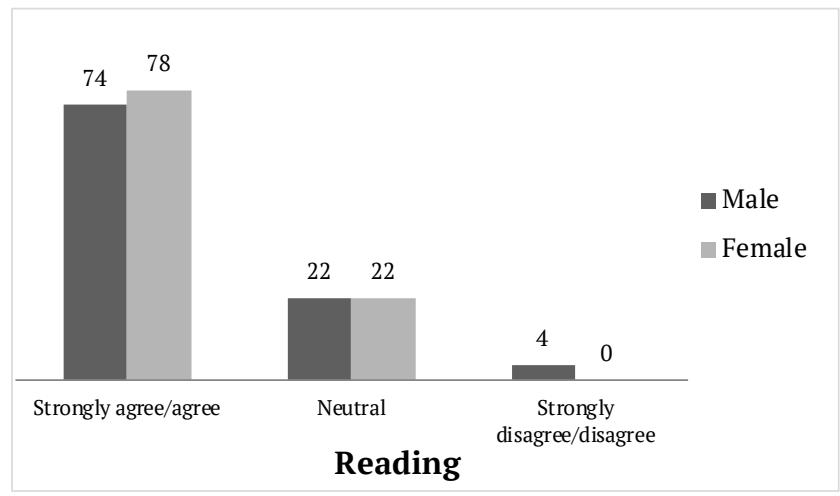

Figure 13. Do you like learning by reading? (percentages).

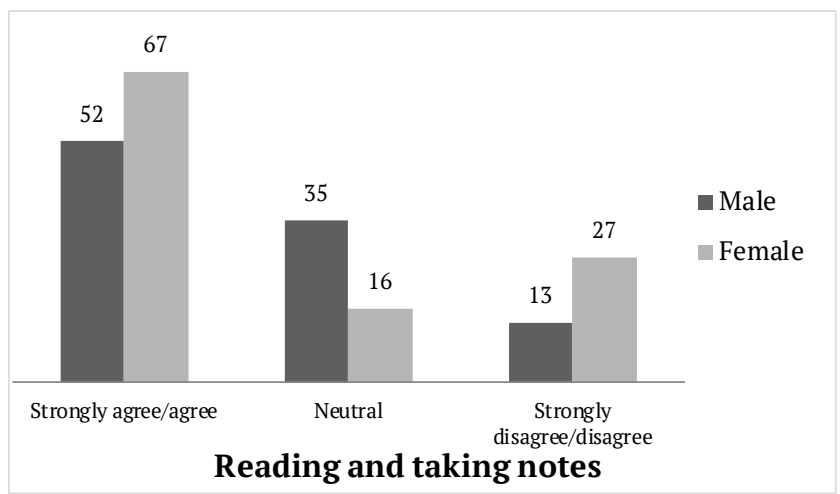

Figure 14. Do you like learning by reading and taking notes? (percentages).

\section{Writing/analytical skills}

Bulgarian students' preferences on writing activities varied considerably between rather negative and some surprisingly positive answers. When asked, "When learning new vocabulary, do you like learning by saying or writing words several times?", female students expressed positive attitudes with 43 percent agreeing, while male students' opinions tended to be more on the negative end of the spectrum with 48 percent (See Figure 19).

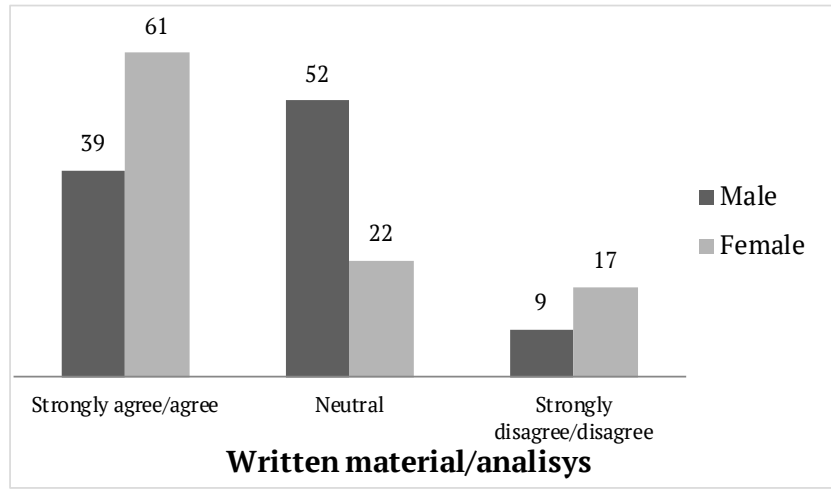

Figure 15. Do you like learning from analysing written material? (percentages).

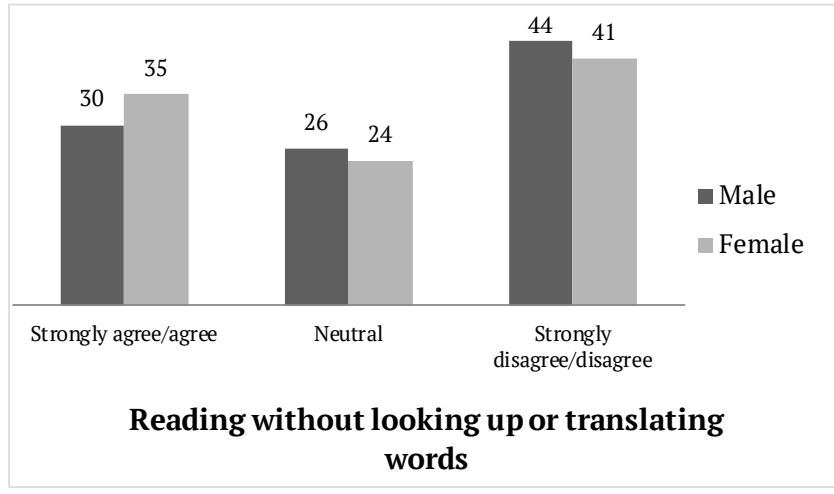

Figure 16. When learning new vocabulary do you like learning by reading without looking up or translating words? (percentages).

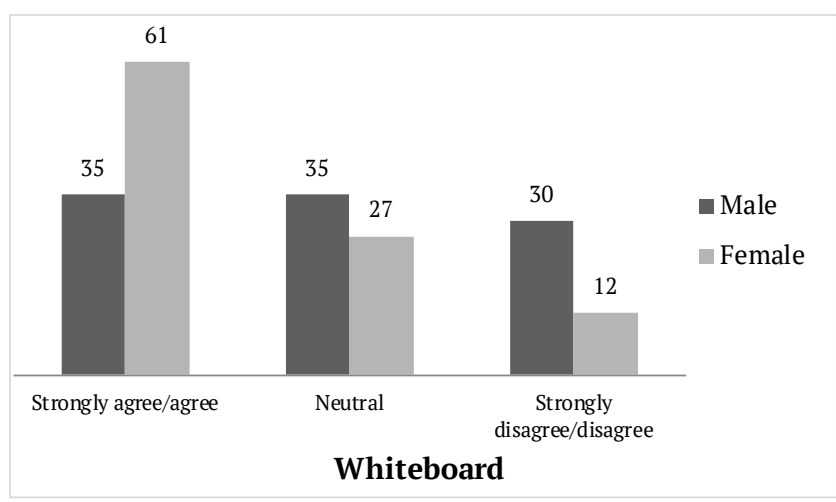

Figure 17. Do you like learning from the whiteboard? (percentages).

The question "Do you like learning by making summaries?" showed strongly divided opinions. Fortyfive percent of the males liked this activity, but females' opinions tended to be neutral at 42 percent, while the negative answers amounted to 32 percent on the males' side and to 24 percent on the females' (See Figure 20). One of the most unexpected results emerged from the answers to the question " Do you like learning by writing homework regularly?" Half of the male students agreed or strongly agreed on the usefulness and likeability of this task, while the other half's opinions were evenly 


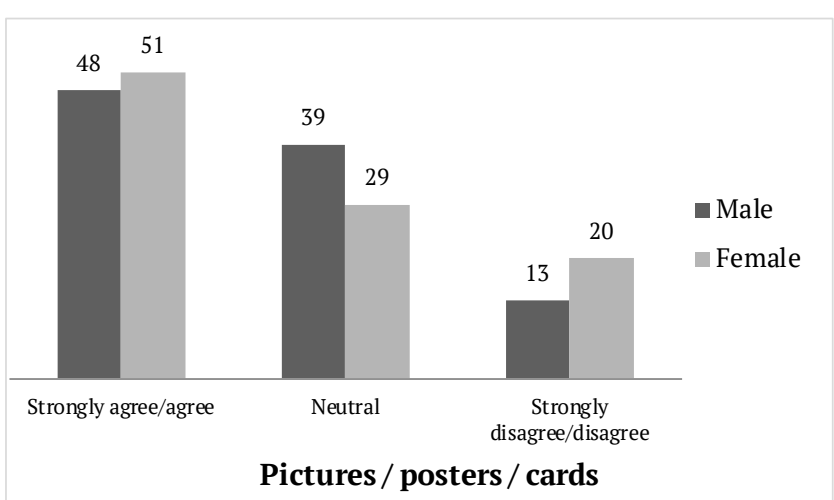

Figure 18. Do you like learning from pictures, posters, and/or cards? (percentages).

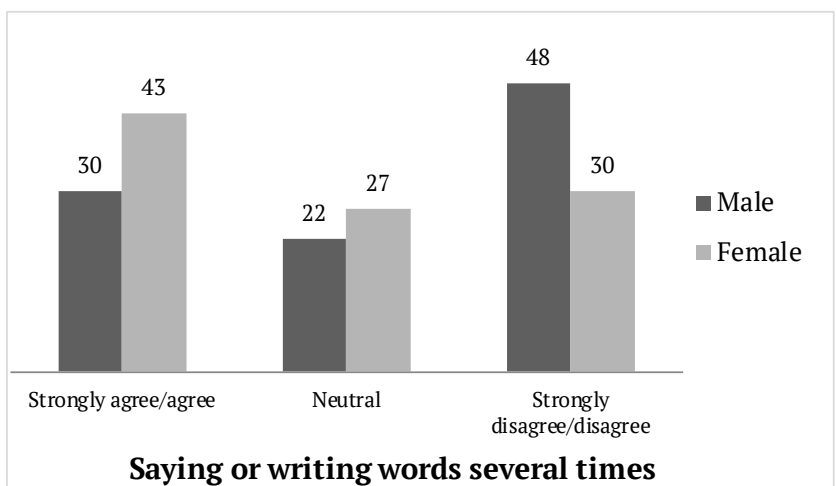

Figure 19. When learning new vocabulary, do you like learning by saying or writing words several times?

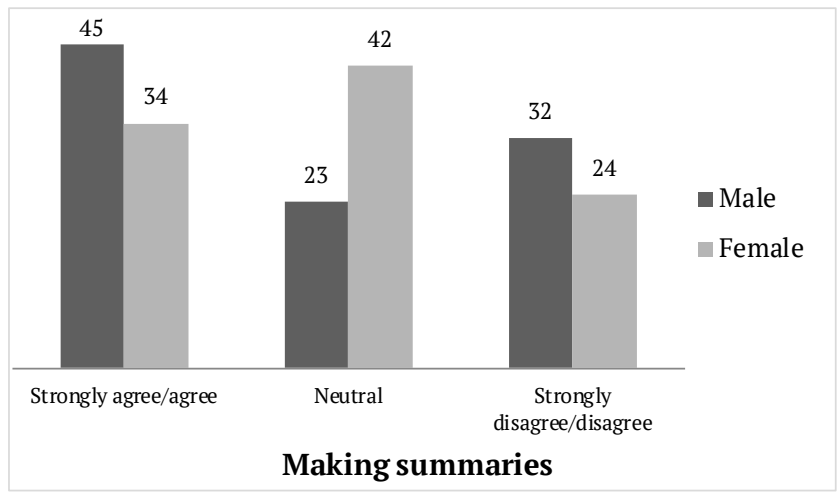

Figure 20. Do you like learning by making summaries? (percentages).

distributed between neutral and negative answers. Also, the majority of female students had high esteem for writing regularly homework, while 20 percent were neutral and only 15 percent had negative viewpoints on the attractiveness of such a task (See Figure 21). The answers to the question "Do you like writing a learning diary?" were moderately positive. Fifty-two percent of the males and a 44 percent of the females clearly disliked this activity, while between 28 and 29

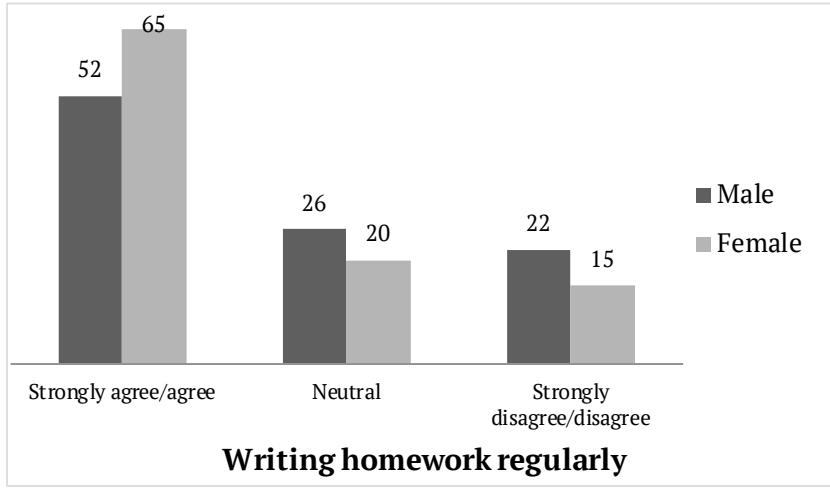

Figure 21. Do you like learning by writing homework regularly? (percentages).

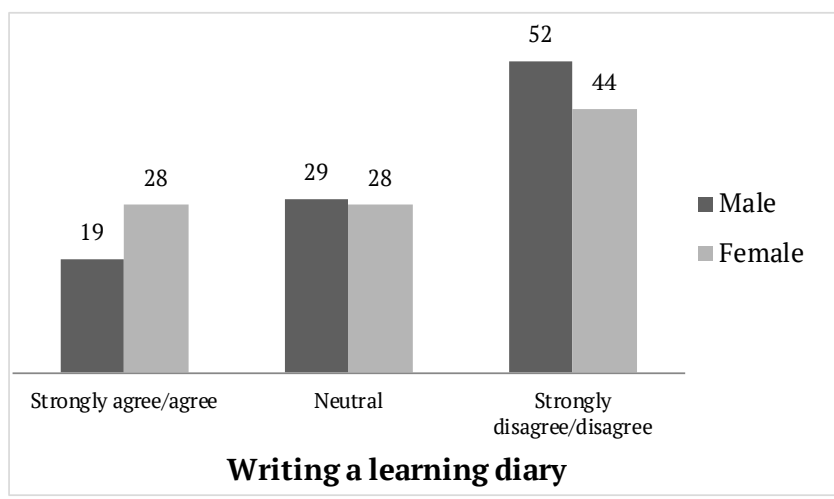

Figure 22. Do you like writing a learning diary? (percentages).

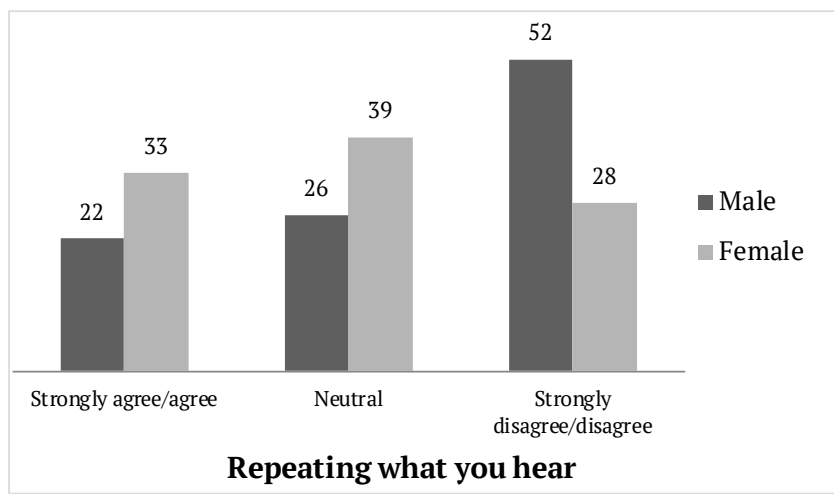

Figure 23. Do you like repeating what you hear? (percentages).

percent were neutral. Only 19 percent of the males liked writing a learning diary, while females' responses were somewhat more positive at 28 percent (See Figure 22).

\section{Speaking/creative skills}

Bulgarian students' opinions on speaking activities reflect the above-mentioned language anxiety to a certain degree. To the question "Do you like repeating 


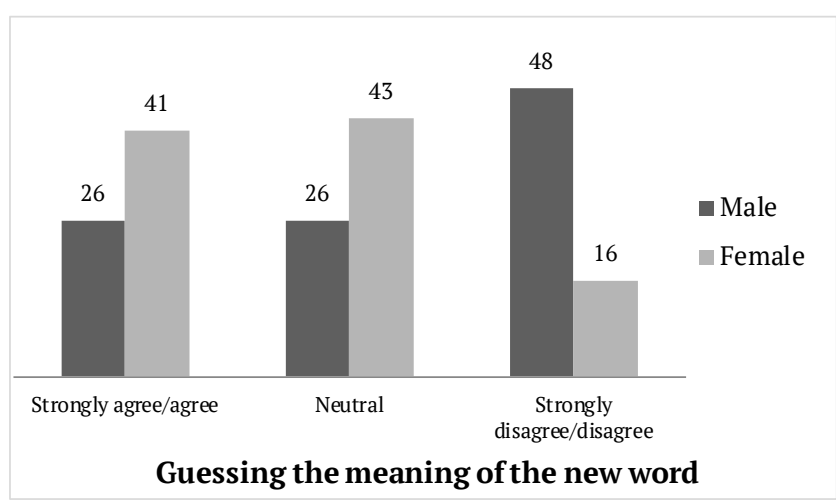

Figure 24. When learning new vocabulary, do you like guessing the meaning of the new word? (percentages).

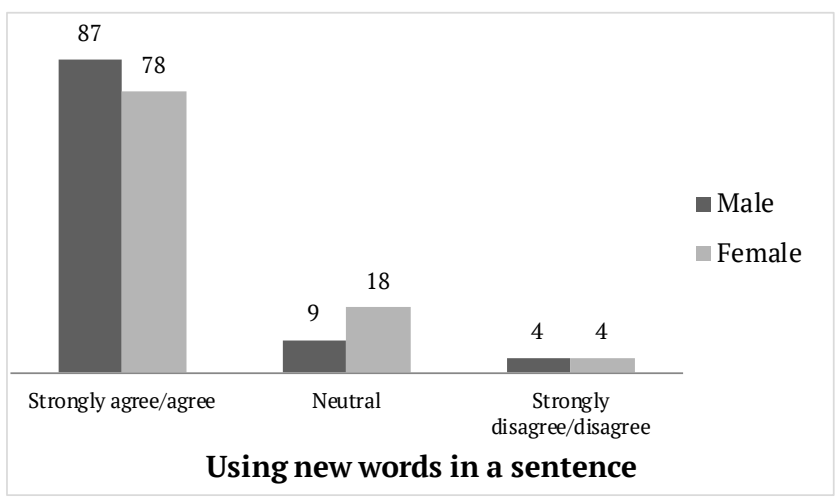

Figure 25. When learning new vocabulary, do you like using new words in a sentence? (percentages).

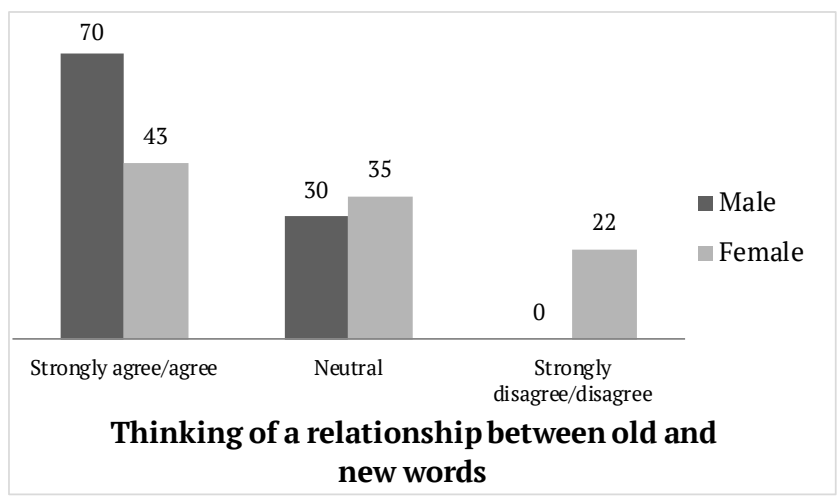

Figure 26. When learning new vocabulary, do you like thinking of a relationship between old and new words? (percentages).

what you hear?", half of the males expressed negative opinions, while females showed neutral attitudes at 40 percent (See Figure 23). Similarly, to the question "When learning new vocabulary, do you like guessing the meaning of the new word?", almost half of the male participants' answers reflected dislike, while female participants were mostly divided among positive and neutral opinions (See Figure 24).

Although guessing the meaning of new words was clearly not favoured by the majority, answers to

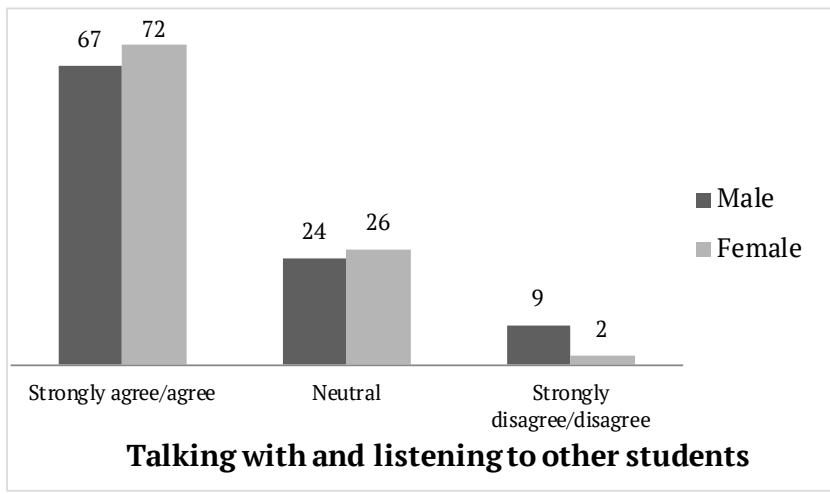

Figure 27. Do you like talking with and listening to other students? (percentages).

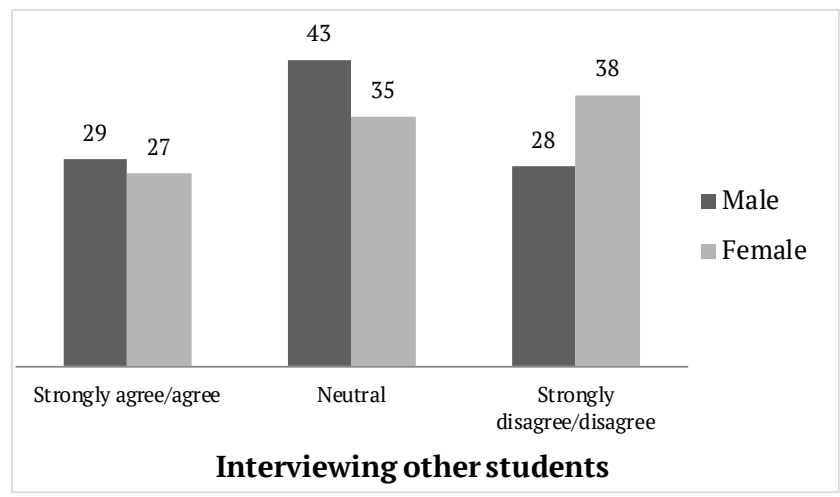

Figure 28. Do you like interviewing other students? (percentages).

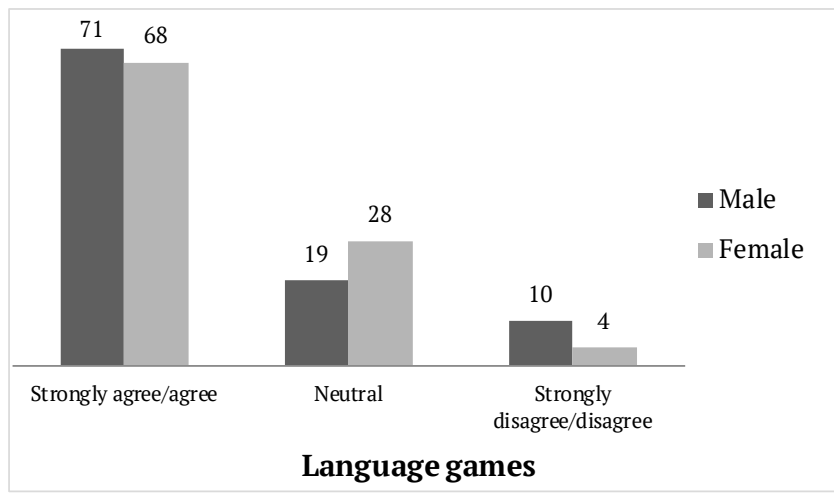

Figure 29. Do you like language games? (percentages).

the question "When learning new vocabulary, do you like using new words in a sentence?" reflected more positive attitudes on both parts (See Figure 25). These opinions may suggest that once the basic vocabulary and language skills are developed, students enjoy building speech strategies and increasing fluency. The question "When learning new vocabulary, do you like thinking of a relationship between old and new words?" divided opinions, this being the strategy more successful among males, while females' opinions were 


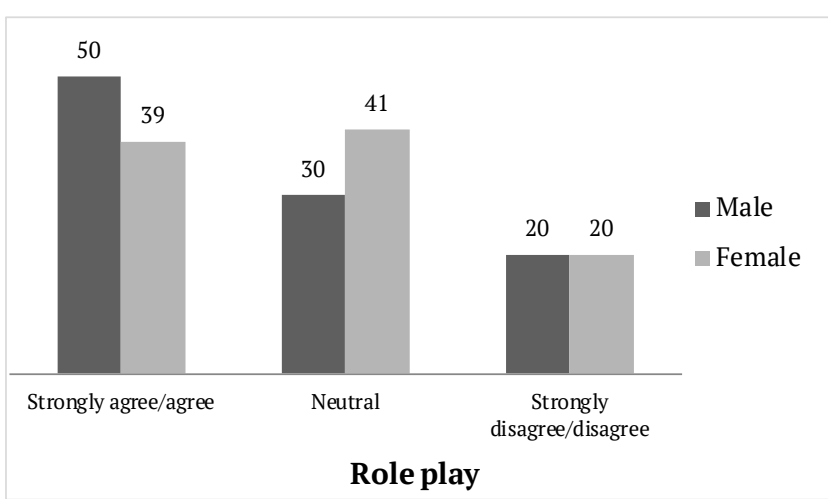

Figure 30. Do you like role playing? (percentages).

rather mixed, tending to be slightly more positive and neutral (See Figure 26). Both male and female students expressed favourable viewpoints when asked "Do you like talking with and listening to other students?" (See Figure 27). However, when asked "Do you like interviewing other students?", viewpoints pointed towards the neutral and negative end of the spectrum (See Figure 28). When asked "Do you like language games?", most respondents expressed very favourable opinions (See Figure 29). Similarly, to the question "Do you like role playing?", half of the males were positive, while most of the females' opinions were divided among positive and neutral (See Figure 30). However, in rather sharp contrast, the majority of the participants disliked or had neutral attitudes when asked "Do you like memorising conversations or dialogues?” (See Figure 31).

\section{Discussion}

The results, in percentages, were analysed according to the four main skills, namely listening, reading, writing, and speaking. The individuals' genders and individual versus group working preferences were also taken into account. The findings obtained from this study offer some notable insights, suggesting that learning style preferences are of vital importance to consider.According to the data, learners' most preferred ways of learning English were in small groups, and in the case of most females, individually. On the other hand, at least half of the participants clearly disliked studying in large groups. In any case, some figures showed that a noticeable number of students had no clear preference on working individually, in pairs, or in groups. If taken positively, this may indicate the adaptability of Bulgarian students for the sake of learning. However, the number of neutral answers may be due to either a lack of interest on the topic while filling out the questionnaire or a lack of motivation in attending the lessons altogether.

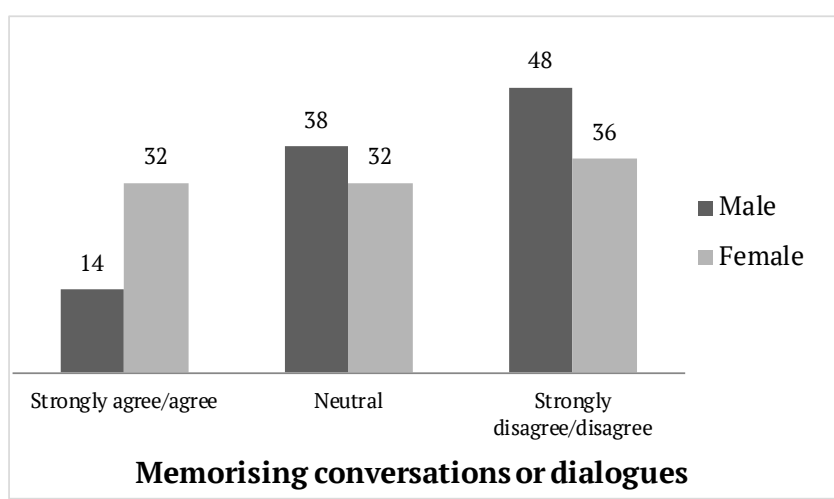

Figure 31. Do you like memorising conversations or dialogues? (percentages).

As for the listening activities, the results showed that most students preferred listening activities when accompanied by visual aids, in particular TV, videos, or films, yet, karaoke and lyrics fill-in activities were an obvious exception to this. The opinions showed that learners liked, or at least were neutral, when guest speakers (using body language and gestures) delivered information, but listening activities that required solely listening skills, such as in the case of the radio or podcasts, were viewed as mostly negative.

The case of reading in a second language is definitely a favoured activity among the participants, particularly when accompanied by visual materials that may help deciphering and constructing the meaning of the text. However, opinions were more neutral in the areas where students were supposed to use their capacity to guess the meaning of new words, or using their ability to predict the general message of the text by relying on their previous knowledge.

Writing activities were viewed with moderate success. Students disliked repetitive tasks, such as writing words several times for the sake of memorising them. However, writing homework and making summaries were among the most enjoyable tasks. It seems that writing activities that rely on students' previous knowledge or the production of short synopses of texts encourage learners to move out of their comfort zones with secure steps.

Speaking exercises caused a division of opinions as well. Students mostly disliked repeating words and expressions to be learned, memorising dialogues, guessing the meaning of a new word, and interviewing other students. More positive attitudes could be observed when the activity was related to using words in a new sentence, thinking of relationships between old and new words, talking to other students, role play, and language games. Therefore, it is safe to say that inspiring, amusing, and brainstorming activities that are placed in a relaxed atmosphere were largely favoured by both genders.

The often diverse opinions suggest that learners are not fully aware of their learning strengths and 
learning style preferences. Therefore, both educators and students should consider ways to uncover and recognize the areas where learning strengths can be reinforced and learning styles can be expanded for the sake of enhancing foreign language learning strategies.

The findings were sometimes unexpected. The result that corroborates previous theories is that many learners were not aware of their learning style preferences, and had no clear learning strategies in the context of learning a foreign language. Also, language anxiety prevented some students from liking and/or readily participating in certain activities that could further enhance their achievement. However, the eagerness of writing homework and engaging in small-group talking and problem solving suggests that students had rather strong intrinsic motivation to learn English. Therefore, these results may be interpreted as a lack of proper guidance in discovering, understanding, and developing the student's individual learning style preferences. With the educators' assistance, these skills could open new horizons in foreign language learning, enabling learners to better comprehend and widen their cognitive capacities.

\section{Conclusion}

Given its strong psychological and cultural implications, learning a second/foreign language is a highly complex task to undertake. Therefore, it is important to notice that, although learners may have consolidated learning style preferences in other subjects or domains, their approach may need to be re-negotiated and expanded when learning a new language. Addressing and comprehending students' learning style preferences and competence is a dual responsibility. Educators should facilitate diverse activities, educational materials, and assessment methods in order to help students find the most appropriate learning styles to gain and strengthen knowledge. During this process, students should consolidate and internalise concepts, build new strategies on already acquired knowledge, and utilize opportunities to engage in practicing English with their peers. Also, advising students on their learning strengths may eventually empower them to overcome new challenges and persevere in remembering new structures and difficult information while maintaining focus, motivation, and grit. Teacher training institutions should place more emphasis on certain psychological aspects of teaching, such as student motivation and paralanguage. These skills may help future teachers decipher students' attitudes in order to guide learners according to their individual needs and teach students to be more self-conscious of learning strategies. Mutual respect between students and teachers is fundamental in this area, since learning style preferences are part of students' character and identity (Mehrdad \& Ahghar, 2013, p.105). Although this research provides readers with practical data, the limitations are not to be overlooked. Further research is needed to better determine how English teachers' nationality, teaching style, student motivation skills, attitude, and capability to guide learners to find and develop their learning strengths affect learning success. The second part of this research will attempt to answer to these questions.

\section{References}

Archibald, A. (2004). Writing in a Second Language. Subject Centre for Languages, Linguistics and Area Studies Guide to Good Practice. Retrieved from: https://www.llas.ac.uk/resources/gpg/2175

Arias, Y, B. \& García, O.L.N. (2013). How effective is cooperative learning in EFL/ ESL Teaching/Learning Process? Retrieved from: http://repositorio.utp.edu.co/dspace/ bitstream/handle/11059/4038/42840712B642. pdf?sequence $=1$

Bada, E. \& Okan, Z. (2000). Students' Language Learning Preferences. TESL-EJ, 4(3). Retrieved from: http://tesl-ej.org/ej15/a1.html

Brown, J.S., Collins, A. \& Duguid, P. (1989). Situated Cognition and the Culture of Learning, Educational Researcher, 18(1), 32-42.

Burns,A.(2012).AHolisticApproach to Teaching Speaking in the Language Classroom. Paper presented at: 25 th ETA-ROC Anniversary Conference: Epoch Making in English Language Teaching and Learning, Taipei, Taiwan. Retrieved from: http://www.andrasprak. su.se/polopoly_fs/1.204517.1411636356!/menu/ standard/file/Anne Burns.pdf

Buttery, T. J. (1980). Listening: A skill analysis. Education, 101(2), 181.

Chomsky, N. (1979). Language and responsibility. New York, NY: Martin's Press.

Dörnyei, Z. \& Csizér, K. (2012). How to design and analyse surveys in SLA research? In A. Mackey \& S. Gass (Eds.), Research Methods in Second Language Acquisition: A Practical Guide (pp. 74-94). Malden, MA: Wiley-Blackwell.

Folley, S. (2015). The Effect of Visual Cues in Listening Comprehension: Pedagogical Implications for Non-Native Speakers of English. Culminating Projects in English. 39. Retrieved from: http:// repository.stcloudstate.edu/cgi/viewcontent. 
cgi?article $=1037 \&$ context $=$ engl_etds

Frawley, W. (1997). Vygotsky and Cognitive Science: Language and the Unification of the Social and Computational Mind. Cambridge, MA: Harvard University Press.

Goh, C. C. M., \& Burns, A. (2012). Teaching speaking: A holistic approach. New York, NY: Cambridge University Press.

Grimm, D. (2004). Individual learning versus group learning in a suburban second grade classroom (Unpublished MA thesis), Rowan University, Glasboro.

Guiora, A. Z. (1983). The Dialectic of Language Acquisition, An Epistemology for the Language Sciences. Language Learning, 33(5), 3-12.

Gullberg, M. \& McCafferty, S. (2008). Introduction to gesture and SLA: Toward an integrated approach. Studies in Second Language Acquisition, 30(2), 133146.

Horowitz, D. M. (1986). What professors actually require: Academic tasks for the ESL classroom. Tesol Quarterly, 20(3), 445-462.

Huguet, A.., \& Llurda, E. (2001). Language Attitudes of School Children in Two Catalan/Spanish Bilingual Communities. International Journal of Bilingual Education and Bilingualism, 4(4), 267-282.

Johnson, K. (1996). Language teaching and skill learning. Oxford, Blackwell.

Karim, K. (2003). First language (Ll) influence on second language (L2) reading: The role of transfer. Retrieved from: http://www.mmduvic.ca/index.php/WPLC/ article/download/5164/2136

Kecskes, I. (2008). The effect of the second language on the first language, Babylonia. 2, 30-34.

Krashen, S. D. (1984). Writing: Research, theory, and applications. Oxford, Pergamon Press.

Lems, K., Miller, D. L., \& Soro, M. T. (2010). Teaching reading to English learners. Insight from Linguistics. New York, NY: The Guildford Press.

Long, M. H., \& Porter, P. A. (1985). Group Work, Interlanguage Talk, and Second Language Acquisition. TESOL QUARTERLY, 19(2), 208-229.

Mehrdad, A. G., \& Ahghar, M. R. (2013). EFL Students' Language Learning Preferences at Islamic Azad University-Hamedan Branch. Procedia - Social and Behavioral Sciences, 93, 102-106.

Mikulecky, B. S. (2008). Teaching reading in a Second Language. Retrieved from: http://www. longmanhomeusa.com/content/FINAL-LO\%20 RES-Mikulecky-Reading\%20Monograph\%20.pdf

Moenikia, M., \& Zahed-Babelan, A. (2010). The role of learning styles in second language learning among distance education students. Procedia Social and
Behavioral Sciences, 2, 1169-1173.

Moores-Abdool, W., Yahya, N., \& Unzueta, C. H. (2009). Learning preferences of Saudi university students with native English speaking teachers. Paper presented at the International Conference of the Kingdom of Saudi Arabia Association of Language Teachers (KSAALT), Al-Khobar, Kingdom of Saudi Arabia. Retrieved from: https://eric.ed.gov/?id=ED510952

Mulalic, A., Shah, P.M., \& Ahmad, F. (2009). LearningStyle preference of ESL students. ASEAN Journal of Teaching and Learning in Higher Education, 1(2) 9-17.

Myles, J. (2002). Second Language Writing and Research: The Writing Process and Error Analysis in Student Text. TESL-EJ, 6(2),1-20.

Oxford, R. (1993). Instructional implications of gender differences in second/foreign language (L2)

learning styles and strategies. Applied Language Learning 4, 65-94.

Raimes, A. (1985). What unskilled ESL students do as they write: A classroom study of composing. TESOL Quarterly, 19(2), 229-225.

Reinders, H. (2010). Towards a Classroom Pedagogy for Learner Autonomy: A Framework of Independent Language Learning Skills. Australian Journal of Teacher Education, 35(5), 40-55.

Samuels, S.J. (2007). The DIBELS tests: Is speed of barking at print what we mean by reading fluency? Reading Research Quarterly, 42(4), 563-566.

Schmidt, R., Boraie, D., \& Kassabgy, O. (1998). Foreign Language Motivation: Internal Structure and External Connections. In R. Oxford (Ed.)., Language Learning Motivation: Pathways to the New Century (pp.9-70). Honolulu: University of Hawai'i

Tanveer, M. (2007). Investigation of the factors that cause language anxiety for ESL/EFL learners in learning speaking skills and the influence it casts on communication in the target language. (Unpublished MA Thesis), University of Glasgow, Glasgow.

Tsang, W. K., \& Wong, M. (2000). Giving grammar the place it deserves in process writing. Prospect, 15(1), 34-45.

Wang, Z. (2014). Review of the influence of L1 in L2 acquisition. CS Canada, Studies on Literature and Language, 9(2), 57-60.

Williams, J. (2012). The potential role(s) of writing in second language development. Journal of Second Language Writing, 21, 321-331.

Yau, M. (1991). The role of language factors in second language writing. In L. Malave \& G. Duquette (Eds.)., Language, culture and cognition: A collection of studies in first and second language acquisition (pp.266-283). Clevedon: Multilingual Matters. 


\section{Appendix A.}

\section{Questionnaire}

\section{HOW DO YOU LIKE LEARNING THE ENGLISH LANGUAGE?}

I would like to ask for your help by answering the following questions concerning English language learning. Don't worry, this is NOT a test and you DON'T have to write your name. Moreover, there are no 'right' or 'wrong' answers. I am very interested in your personal opinions. Please give your answers sincerely. Thank you very much for your help!

Age:

Are you: $\mathrm{Male}$ / $\mathrm{F}$ Female?

IN CLASS DO YOU LIKE LEARNING..

individually?

in pairs?

in small groups?

in a large group?

DO YOU LIKE LEARNING BY...

listening?

reading?

copying from the board?

listening and taking notes?

reading and making notes?

repeating what you hear?

making summaries?

writing homework regularly?

WHEN LEARNING NEW VOCABULARY, DO YOU LIKE LEARNING BY...

using new words in a sentence?

thinking of relationships between old and new words?

saying or writing words several times?

guessing the meaning of a new word?

reading without looking up or translating words?

DO YOU LIKE LEARNING FROM...

Television / videos / films?

Radio / podcasts?

CDs / applications / online?

Written material / analysis?

The whiteboard?

Pictures / posters / cards?

DO YOU LIKE THE FOLLOWING ACTIVITIES IN YOUR CLASS?

Role play

Language games

Songs/Karaoke - fill in the missing words

Talking with and listening to other students

Interviewing other students

Memorising conversations or dialogues

Getting information from guest speakers

Getting information from planned visits (Museums, galleries, etc...) 